\title{
A longitudinal study of independent scholar-published open access journals
}

Bo-Christer Björk, Cenyu Shen, Mikael Laakso

Open Access (OA) is nowadays increasingly being used as a business model for the publishing of scholarly peer reviewed journals, both by specialized OA publishing companies and major, predominantly subscription-based publishers. However, in the early days of the web OA journals were mainly founded by independent academics, who were dissatisfied with the predominant print and subscription paradigm, and wanted to test the opportunities offered by the new medium. There is still an on-going debate about how OA journals should be operated, and the volunteer model used by many such 'indie' journals has been proposed as a viable alternative to the model adopted by big professional publishers where publishing activities are funded by authors paying expensive article processing charges (APCs). Our longitudinal quantitative study of 250 'indie' OA journals founded prior to 2002, showed that $51 \%$ of these journals were still in operation in 2014 and that the median number of articles published per year had risen from 11 to 18 among the survivors. Of these surviving journals only $8 \%$ had started collecting APCs. A more detailed qualitative case study of five such journals provided insights into how such journals have tried to ensure the continuity and longevity of operations. 
1 A longitudinal study of independent scholar-published open 2 access journals

3

${ }^{1}$ Department of Management and Organization, Information Systems Science, Hanken School of Economics, Helsinki, Finland

9 Corresponding Author:

10 Cenyu Shen ${ }^{1}$

11 Arkadiankatu 22, Helsinki, 00101, Finland

12 Email address: cenyu.shen@hanken.fi

13

14

15

16

17

18

19

20

21

22

23

24

25

26

27

28

29

30

31

32

33

34

35

36

37

38

39

40

41

42 
44

45

46

47

48

49

50

51

52

53

54

55

56

57

58

59

60

61

62

63

64

65

66

67

68

69

70

71

72

73

74

75

76

77

78

79

80

\section{Abstract}

Open Access (OA) is nowadays increasingly being used as a business model for the publishing of scholarly peer reviewed journals, both by specialized OA publishing companies and major, predominantly subscription-based publishers. However, in the early days of the web OA journals were mainly founded by independent academics, who were dissatisfied with the predominant print and subscription paradigm, and wanted to test the opportunities offered by the new medium. There is still an on-going debate about how OA journals should be operated, and the volunteer model used by many such 'indie' journals has been proposed as a viable alternative to the model adopted by big professional publishers where publishing activities are funded by authors paying expensive article processing charges (APCs). Our longitudinal quantitative study of 250 'indie' OA journals founded prior to 2002 , showed that $51 \%$ of these journals were still in operation in 2014 and that the median number of articles published per year had risen from 11 to 18 among the survivors. Of these surviving journals only $8 \%$ had started collecting APCs. A more detailed qualitative case study of five such journals provided insights into how such journals have tried to ensure the continuity and longevity of operations.

\section{Introduction}

\section{Background}

Individual scientists or groups of scientists were the first to take advantage of the Internet and the web for dramatically re-engineering the publishing of scholarly peer reviewed journals in creating Open Access (OA) journals. Commercial publishers or scientific societies, who have dominated traditional subscription-based publishing of academic journals, have followed much later. In the mid 1990s electronic only publishing in conjunction with the OA model seemed ideologically right and suddenly the threshold for starting a journal had dramatically lowered. All that was needed was some server space at the university of one of the editors, someone who mastered a bit of web programming and an enthusiastic group of academics to spread the word via email and academic conferences.

Most of the OA journals founded in the 1990s were of this variety, later many established subscription journals (particularly society ones) have made their digital versions freely available immediately or with a delay. This has been particularly noticeable in countries where cheap or free national or regional electronic portals have become available, like Scielo, Redalyc, and Jstage. Since around 2003 the OA market has become increasingly dominated by professionally 
81 published journals, which finance themselves by charging authors so-called article processing

82 charges, APCs. First such journals were being launched by open access publishers like

83 BioMedCentral and PLOS but in the last couple of years the major commercial and society

84 publishers have increasingly started new OA journals and have also converted some subscription

85 journals to APC-financed models.

86

87 Over the years a debate has been raging about the sustainable expenditure for publishing

88

89

90

91

92

93

94

95

96

97

98

99

100

101

102

103

104

105

106

107

108

109

110

111

112

113

114

115

116

\section{Earlier Studies}

118 A number of previous studies, both snapshots and some with longitudinal elements, have shed

119 light on different aspects of such type of journals, which for short we will call "indie" journals. 
120

121 Hitchcock et al. (1996) studied electronic English language STM journals available in September

122 1995. 44 of the 83 relevant journals that they found first appeared in 1995. The share of OA

123 journals varied strongly depending on the type of publisher, with $27 \%$ for commercial

124 publishers, $52 \%$ for scientific societies and $96 \%$ for others (mainly university departments).

125

126 Harter and Kim (1997) identified 131 electronic journals, which were active in 1996, of which

12777 were judged to be peer reviewed journals (of these 39 had published articles in 1993 or

128 before). Since their study was based on e-journal lists compiled in the US, the study had a strong

129 bias to English-language journals. The hard sciences, social sciences and humanities had about

130 equal shares, with the most popular topics being education, literature, mathematics and library

131 and information science. $69 \%$ of the journals had only an electronic version while the rest were

132 published in parallel in print. $88 \%$ of the journals were OA.

133

134 The MSc thesis of Wells (1999) was the first to explicitly focus on scholarly or peer reviewed

135 journals, which were free to read (the term Open Access came into use only around 2002). She

136 was able to identify 387 such journals. Probably due to the journal lists she had used as a starting

137 point, over half the journals were published in the US. Overall the vast majority of journals

138 (around 90\%) had started publishing in 1994-1998. Her statistics about the organization/person

139 responsible for publishing the journal was interesting: 56\% academic, $14 \%$ learned society, $13 \%$

140 commercial and $17 \%$ other types. For the electronic only journals, $37 \%$ were in the social

141 sciences, $20 \%$ in life sciences, $19 \%$ in arts and humanities, $14 \%$ in the physical sciences and $9 \%$

142 in engineering. The overall mortality rate of journals (where the website could not be found or

143 which had not published articles in 1998-1999) was $25 \%$. The highest mortality rates were

144 observed in journals within social science (43\%) and humanities (21\%).

145

146 The first study to look more explicitly at the fate of early OA journals was Crawford (2002). He

147 grouped 104 journals that had been listed in the Association of Research Libraries' (ARLs')

148 Directory of Electronic Journals, Newsletters and Academic Discussion Lists for 1995 depending

149 on their publication output between 1993 and 2000. He found that 27\% were publishing

150 substantial amounts of articles, 20\% still published small but steady flows of articles, and that

$15119 \%$ seemed "to have fallen prey to the arc of enthusiasm: after a few good years, the journals

152 had died or become comatose". For the rest of the journals their websites were confusing or

153 could not be found.

154

155 Our own research group studied OA journals in 2002-2003, using in particular Wells (1999)

156 study as a major input. In the first phase of the study (Gustafsson, 2002) 317 OA scholarly

157 journals were identified. Gustafson (2002) also studied the status of the journals identified as

158 active in 1998 by Wells (1999) and found that $50 \%$ were still active in 2002. In the follow-up 
159 study (Hedlund et al, 2004) the editors of all the 317 journals (for which an email address was

160 found) were sent a web survey, for which the response rate was $20 \%$, hence 60 editors answered

161 more detailed questions about their journals. The range of the number of articles published by

162 these 60 journals in 2002 was 3-111, with an average of 20 and a median of 17 . The average rate

163 of acceptance for submissions was $50 \%$ and 6 out of 60 journals were indexed by the Web of

164 Science. The cost structure of publishing the journals was asked in the form of the time

165 allocation for general tasks such as management and IT-infrastructure (250 hours per year) and

166 for the processing of the average article, which was 22 hours.

167

168 In their conclusions Hedlund et al. (2004) ask the question "The key question for OA publishing

169 is whether it can be scaled up from a single journal publishing model with relatively few articles

170 published per year to a comprehensive major journal with of the order of 50-100 articles

171 annually". And they further note: "The continuation of the journal relies very heavily on the

172 personal involvement of the editor and is as such a risk to the model. Employing staff to handle,

173 for example, management, layout and copyediting tasks, is a cost-increasing factor that also is a

174 threat to the model." Both questions are still highly relevant today.

175

176 Since the above studies were carried out, the most significant development affecting the

177 publishing of independent scholar-published journals, has been that free or extremely cheap IT-

178 platforms for publishing journals have become available. In particular the Open source software

179 Open Journals Systems has rapidly become very popular as the basic platform both for

180 publishing articles and for managing the peer review process. OJS is currently used by more than

1818,200 journals (PKP, 2016). Edgar and Willinsky (2010) surveyed 3000 journals using OJS in

1822009 and obtained answers from 998 journal editors. The vast majority of the journals charged

183 neither publication fees nor fees for access, and 83\% were OA. Academic departments (51\%)

184 and scholarly societies (32\%) dominated the picture. The geographic spread included South

185 America with $28 \%$, Asia with $13 \%$ and Africa $7 \%$. Topically the STM sciences had $40 \%$, social

186 sciences $30 \%$ and humanities $11 \%$. The average number of articles published was 31 per year

187 with $74 \%$ publishing $0-30$ articles, and $9 \% 60$ or more. The study also contains interesting data

188 about the workload done, revenues etc.

Since 2009 the OA journal scene has changed considerably with the increased presence of APC funded commercial publishers. The publishers who are members of the Open Access Scholarly

192 Publishers Association (OASPA) published around 140,000 articles in 2014 (Redhead, 2015).

193 Increasingly leading commercial and society publishers are starting new full OA journals or

194 converting existing subscription journals to OA funded by APCs. Unfortunately academics are

195 also swamped with requests to submit to so-called predatory OA journals with deficient or non-

196 existent peer review practices (Shen and Björk, 2015). Much of the debate about Gold OA

197 concerns APC journals and the majority of OA journals which are free to publish in create much

198 less debate, perhaps because many of them are published in languages other than English and in

199 countries outside the US/UK. 
201

202

203

204

205

206

207

208

209

210

211

212

213

214

215

216

217

218

219

220

221

222

223

224

225

226

227

228

229

230

231

232

233

234

235

236

237

238

Offering qualitative insight into the current challenges of small independent scholar-led journals, Morrison (2016) recently interviewed 15 individuals currently involved in producing such journals. Though most believed that the journals would be able to survive in the increasingly competitive OA landscape, many also expressed concerns about their abilities to thrive with existing reliance on external subsidy funding and the level of technical support currently available to them.

The question remains, how sustainable has the independent scholar-published OA journal model been for journals who adopted the model early? The major advantage of these journals some 20 years ago as well as today is that they are rarely based on APC-funding which might be an obstacle for some potential authors without means or mechanisms to fund them.

\section{Methods}

So far a lot of the discussions (for instance in e-mail discussion lists) about the viability of the 'indie' model has been rather speculative and based on the reporting of anecdotal success stories. Now that over 20 years have passed since the first proper wave of journals founded based on an OA publishing model, there is sufficient longitudinal data available to evaluate the sustainability of the OA model for these early independent OA journals.

The study consists of a quantitative and a qualitative part. The quantitative part builds upon OA journal listings from early OA studies of Wells (1999), Crawford (2002), and Hedlund et al. (2004). The list of journals from these studies were aggregated into a master list of 264 journals, after which non-independent (e.g. commercially-published, society-published) and journals which had converted from print to OA were removed from the sample (14 in total), resulting in a population of 250 'indie' journals in our study. Each of the journal websites were visited during the second half of 2015 in order to record longitudinal published article volumes, focusing on collecting data about peer-reviewed articles and leaving out editorials and other non-core contents. Some of the earlier studies had already collected and published article volumes and in such cases that data was used and extended. Where available Scopus or DOAJ was used to collect bibliometric information for journals, however, for most the collection was handled manually. It is a cohort type of study, concentrating on journals founded as OA journals prior to 2002 and which we knew were active in that cut-off year. Due to the limited number of journals included in the population sampling was not needed, the whole population was observed.

In the qualitative part the development of five successful 'indie' journals over the past twenty years are described as a multiple case study. The focus is on how the work has been organized and on possible changes in strategies during this time. 


\section{Results and Discussion}

240

\section{Quantitative Results}

242

243

244

245

246

247

248

249

250

251

252

253

254

255

256

257

258

259

260

261

262

263

264

265

266

267

268

269

270

271

272

273

274

275

277

\section{Number of active 'indie' journals over time}

In all of the reporting below, 'indie' OA journals which were no longer active and for which no information could be found on the Internet due to completely vanished presence were excluded. When counting the number of OA articles published every year, only articles from journals which have remained with the OA publishing model throughout their lifetime were taken into consideration. Due to a very low number of both 'indie' journals and OA articles in them between 1987 and 1994, the results for journal volumes and article outputs are presented from the year 1995 onwards. For the average OA article per journal, we provided the medians instead of the means due to a highly skewed distribution in the original data, where a couple of very high-volume journals raise the arithmetic mean disproportionately.

Descriptive statistics for the total population of 250 'indie' OA journal founded before 2002 are shown in Table 1. 23 of the journals in the population were categorized as disappeared journals because we could not find their complete information for previous years, they had vanished without a trace and nor was a record of them available from the Internet Archive. As such they can be considered ceased but there is no way of determining when they stopped publishing so they are treated separately in the results. The rate of still active journals of the 250 journals that we studied was $50.8 \%$, meaning that approximately half of them were still publishing.

Among the still active journals, the majority have remained with the OA publishing model, however a small number of journals (9\%) have converted to the subscription-based model. Most of these had been taken over by large commercial publishers using the traditional subscriptionbased publishing model, on average 12 years after they had been launched. The share of 250 'indie' journals that are currently included in DOAJ and Scopus, are 39.6\% and $40.5 \%$ respectively. The reason why Scopus has a slightly higher inclusion rate than DOAJ is likely due to the fact that DOAJ has had a policy of removing non-active journals, while Scopus retains historical records of journals regardless of their status. The results also support the fact that nearly half of 'indie' journals have gained good reputation already, since their inclusion in these major indexes and is consistent with the result that about half of the journals were still active as at 2014.

Table 1: Descriptive statistics for the journals included in the study.

\begin{tabular}{|l|l|l|}
\hline Population: 250 'indie' journals \\
\hline Number of active journals & journals that become subscription journals & 12 \\
\cline { 2 - 3 } & journals that remain with the OA model & 115 \\
\hline Number of ceased journals & 100 \\
\hline
\end{tabular}


278

279

280

281

282

283

284

285

286

287

288

289

290

291

292

293

294

295

296

297

298

299

300

301

302

303

304

305

306

\begin{tabular}{|l|l|}
\hline $\begin{array}{l}\text { Number of disappeared } \\
\text { journals }\end{array}$ & 23 \\
\hline
\end{tabular}

The development over time of active 'indie' OA journals before and after 2002 is shown in Figure 1 (a) and (b). A journal was counted as 'active' in a particular year if it was still publishing articles in that year. Before 2002 the number of active journals grew very rapidly from a total of 76 journals in 1995 to 207 journals in 2002. The year 2002 was the cut-off year to be included in the studied cohort, meaning that no new journals were added to the data set after this point in time. After 2002, the number of journals in the cohort decreased steadily to the 127 that stayed active in 2014.

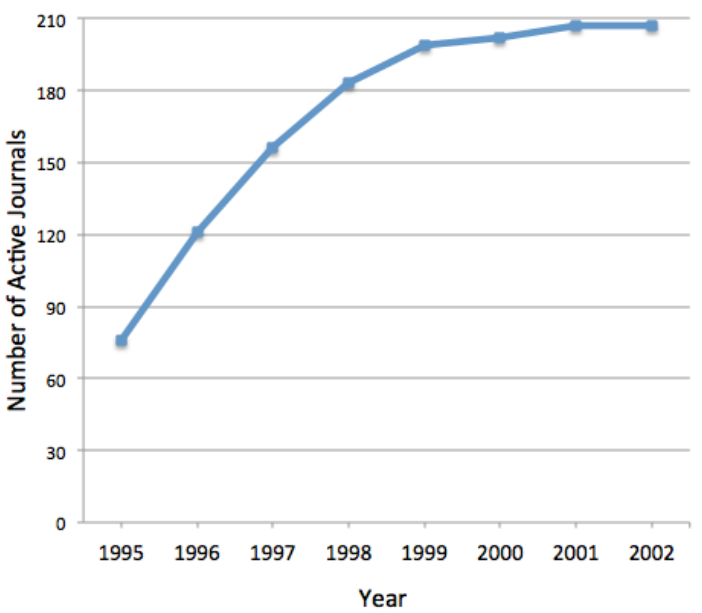

(a)

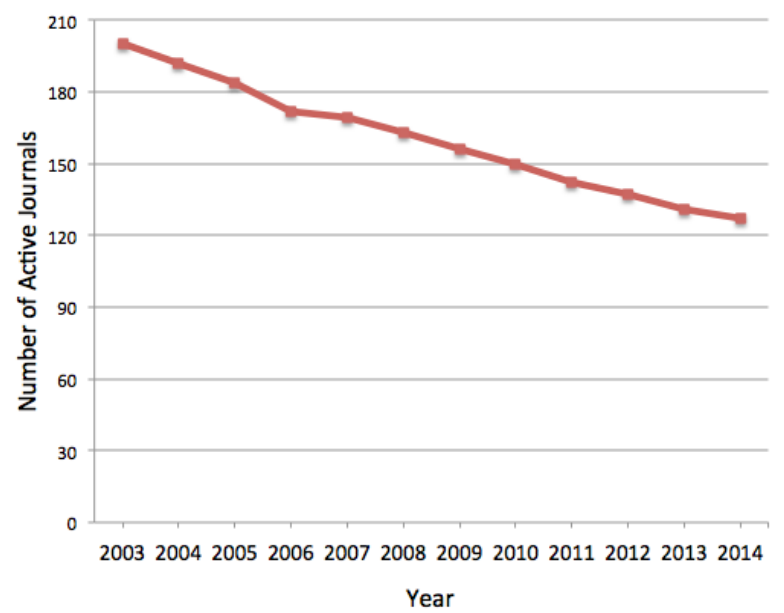

(b)

Figure 1: The number of active 'indie' journals from the cohort of journals founded prior to 2002. (a) Results between 1995 and 2002; (b) Results after no new journals were added from 2003 till 2014.

The share of surviving journals currently charging APCs was also observed, with a result that nearly $8 \%$ among them did so. Clearly this is a viable option for keeping a journal running, provided that the submission levels do not drop significantly after this. It is also an option which is better suited for journals in the hard sciences, in particular health and biomedicine journals, due to the fact that APC-funded OA journals are more common with funding mechanisms more widely established and available to researchers.

\section{Annual median number of articles per journal}

Figure 2 (a) and (b) describe the annual median number of articles published by the 'indie' journals. The number was relatively stable at around 10 articles in the period 1995-2002. This may be the result of many of the journals just having started their existence at that time, with understandably few articles in the first few issues. After 2002, the median for active journals increased steadily from 11 in 2003 to 18 in 2014 . This again is probably a result of the fact that 
307 the surviving journals had already established a good reputation and increased submission numbers during the period, i.e. the stronger getting stronger. The detailed results are included in Table 2 together with other main results for total article volumes. There is a continuous growth in the number of articles published by active journals over the past decades from 862 articles in 1995 to 4954 articles in 2014, despite the fact that no new journals were added after 2002 (when 3563 articles were published). The growth between 2003 and 2014 is explained by the growth of the per journal publishing figures. These findings suggest that at least half of the 'indie' journals are quite sustainable, at least at their current publishing level.

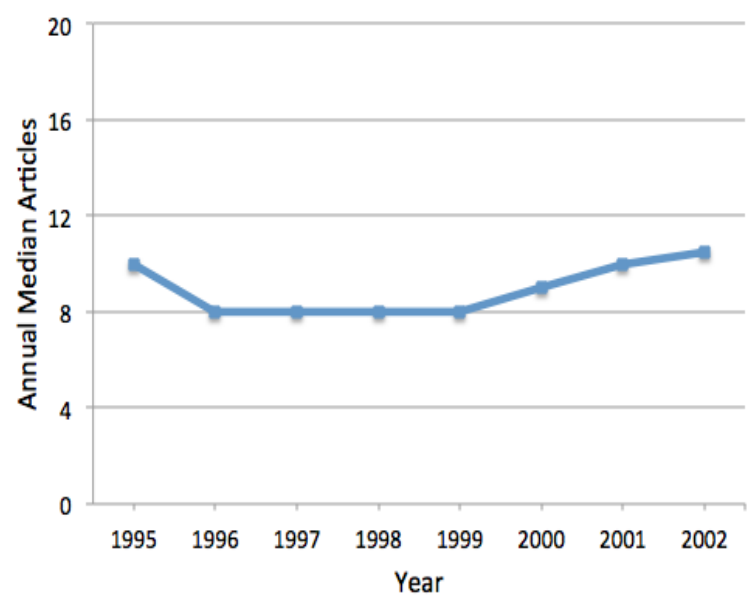

(a)

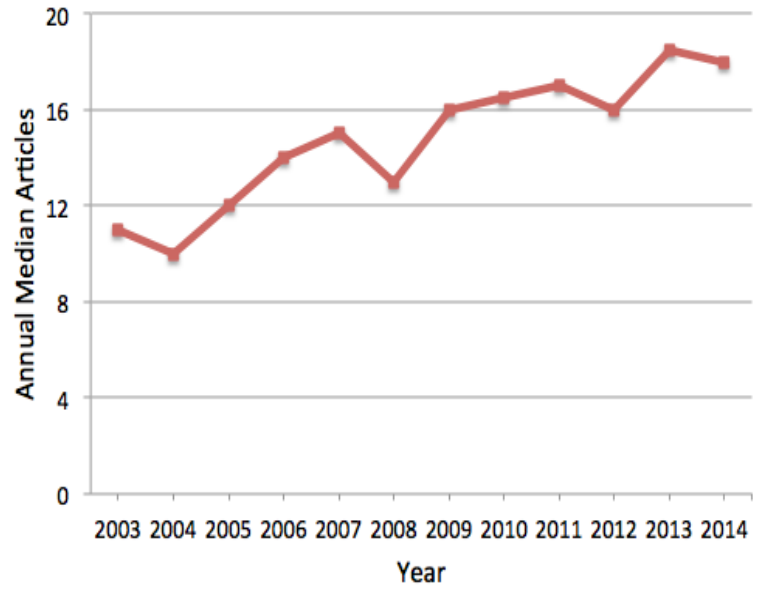

(b)

Figure 2: Annual median number of articles published by 'indie' journals from the cohort of journals founded prior to 2002. (a) Results between 1995 and 2002; (b) Results after no new journals were added from 2003 till 2014.

Table 2: Main results datasheet.

323

\begin{tabular}{|l|l|l|l|l|}
\hline Year & $\begin{array}{l}\text { Annual median } \\
\text { articles per journal }\end{array}$ & $\begin{array}{l}\text { Total number } \\
\text { of articles }\end{array}$ & $\begin{array}{l}\text { Number of } \\
\text { active journals }\end{array}$ & $\begin{array}{l}\text { Number of } \\
\text { ceased journals }\end{array}$ \\
\hline 1995 & 10 & 862 & 76 & 1 \\
\hline 1996 & 8 & 1305 & 121 & 2 \\
\hline 1997 & 8 & 1819 & 156 & 3 \\
\hline 1998 & 8 & 2243 & 183 & 1 \\
\hline 1999 & 8 & 2593 & 199 & 2 \\
\hline 2000 & 9 & 3095 & 202 & 4 \\
\hline 2001 & 10 & 3135 & 207 & 1 \\
\hline 2002 & 11 & 3563 & 207 & 5 \\
\hline 2003 & 11 & 3715 & 200 & 7 \\
\hline 2004 & 10 & 3497 & 192 & 8 \\
\hline 2005 & 12 & 4241 & 184 & 8 \\
\hline 2006 & 14 & 4090 & 172 & 12 \\
\hline
\end{tabular}




\begin{tabular}{|l|l|l|l|l|}
\hline 2007 & 15 & 4394 & 169 & 3 \\
\hline 2008 & 13 & 4760 & 163 & 6 \\
\hline 2009 & 16 & 4681 & 156 & 7 \\
\hline 2010 & 17 & 5083 & 150 & 6 \\
\hline 2011 & 17 & 5290 & 142 & 8 \\
\hline 2012 & 16 & 4934 & 137 & 5 \\
\hline 2013 & 19 & 5298 & 131 & 6 \\
\hline 2014 & 18 & 4954 & 127 & 4 \\
\hline
\end{tabular}

324

325

326

327

328

329

330

331

332

333

334

335

336

337

338

339

340

341

342

343

Age distribution for ceased journals

Figure 3 illustrates at what age ceased 'indie' journals stopped publishing. Most journals survived the first 2-5 years period, whereas the mortality rate rose in the critical 6-9 years period. After that, the number of journals ceasing dropped sharply, indicating that the surviving journals had found stability.

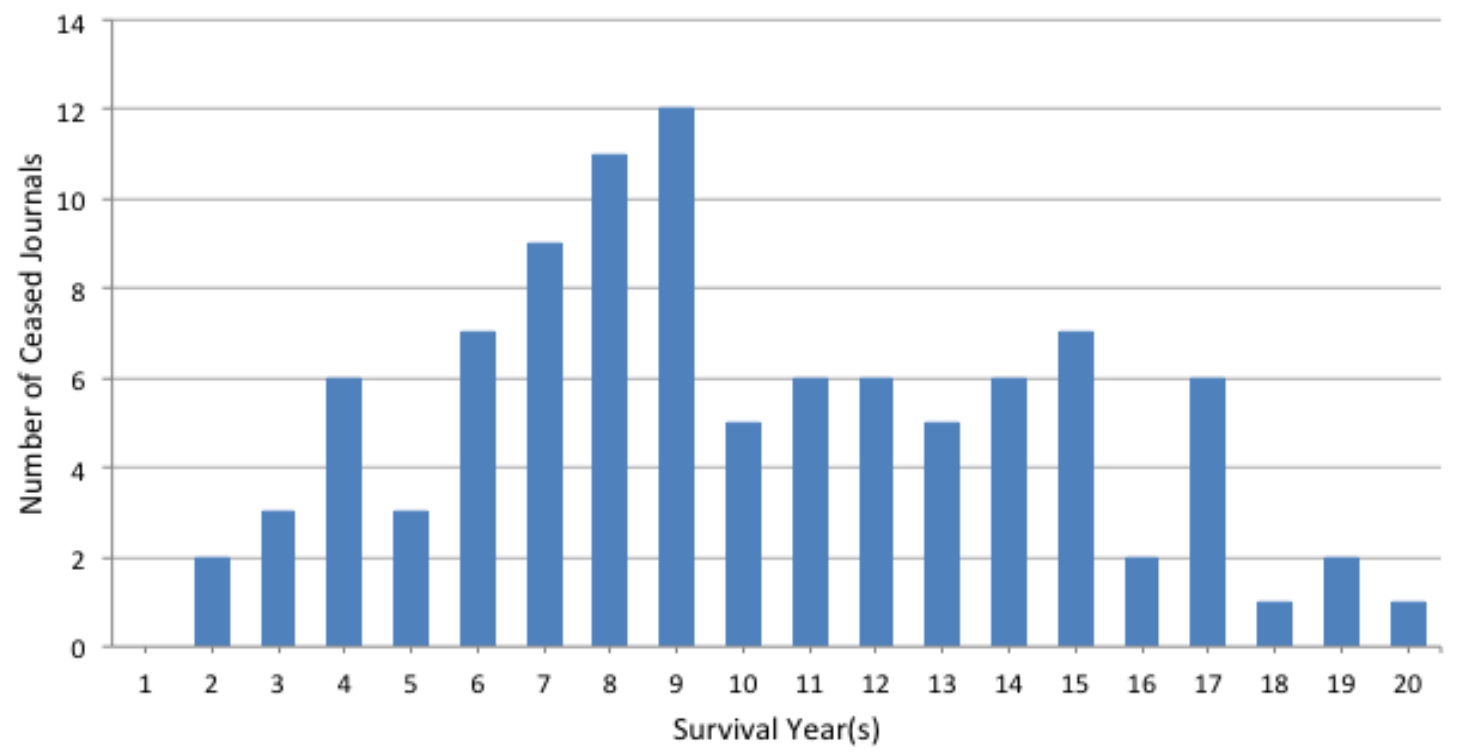

Figure 3. Age distribution for ceased journals.

\section{Subject fields}

Figure 4 describes the distribution of total OA articles published across different subject fields. During the four time periods we studied, the article volumes have shown a fast growth in most disciplines except for chemistry, physics and astronomy as well as business and economics. The largest share of articles was in the social sciences with nearly 8000 articles published in the most recent four years, followed by mathematics with almost 6000 articles. The discipline of earth science and biomedicine ranked third (4123 articles) and fourth (3383 articles). 


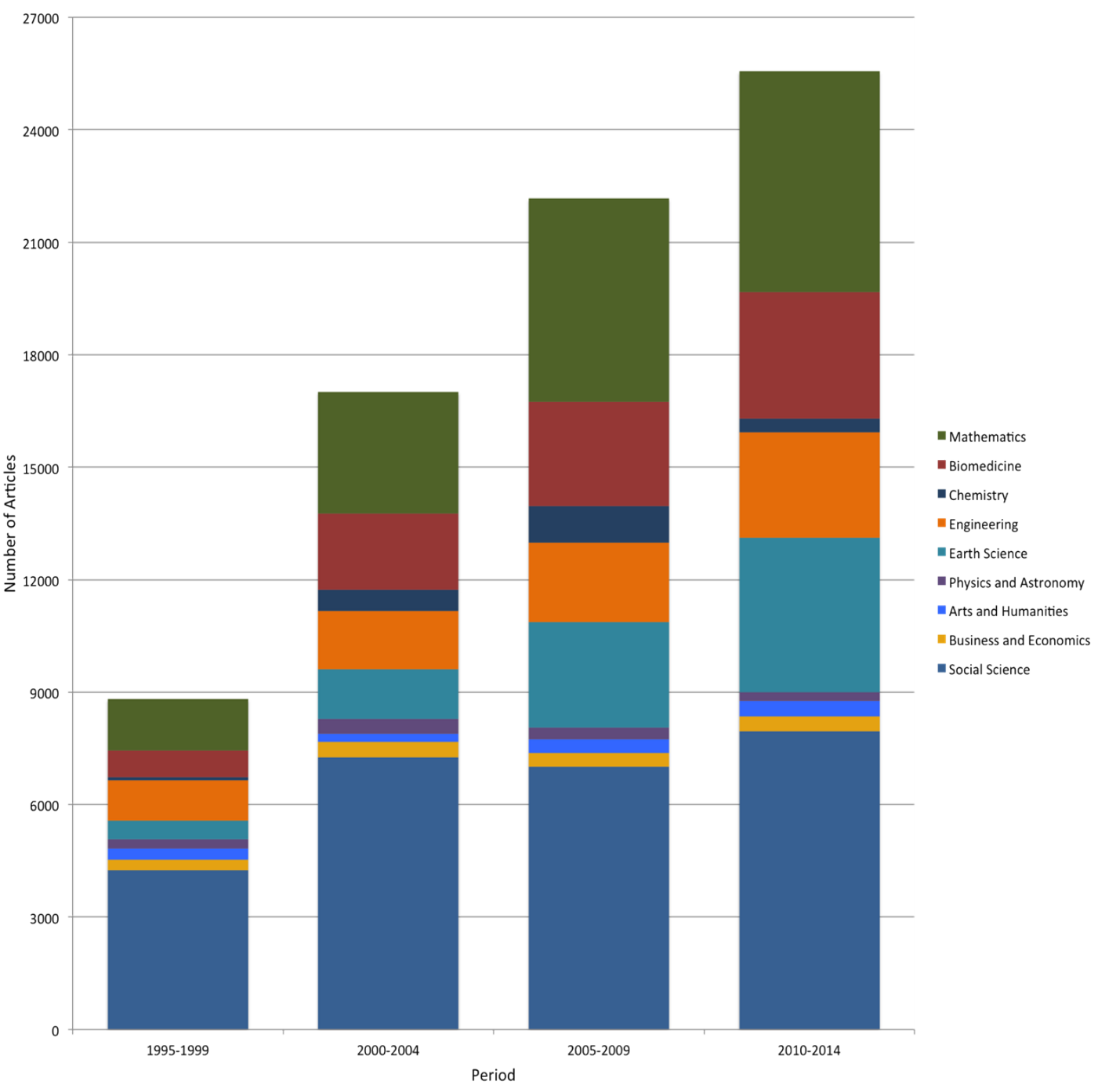

Figure 4: The distribution of $\mathrm{OA}$ article volumes over time and across subject fields.

\section{Five cases}

In the following five case journals, all founded around 1995 are presented. All journals are still surviving and they were picked as a convenience sample, representing slightly differing evolutionary paths. Two of the journals are nowadays charging APCs and one of these has been turned over to a professional OA publishing company. For some of the discussed journals there are published case studies and descriptions available. One of the authors of this article was the founder and long-time editor of ITcon. As for MEO an interview was conducted with the former editor-in-chief.

Electronic Journal of Information technology in construction 
360 The journal, abbreviated ITcon, was founded by four researchers from different parts of the 361 world, active in the same research area, and part of a network meeting at regular yearly 362 conferences (Björk and Turk, 2006). The first author of this study was the editor-in-chief, and 363 hence the official publisher was at first his university at the time being. Later when he moved to 364 another university an international organization of building researchers was asked to be the 365 official publisher, but this has in fact been a "rubber stamp". The web server used has all the time 366 been at the university of another one of the co-editors, who also programmed the first software 367 needed to publish articles. The software has undergone a couple of revisions, partly indirectly 368 funded via an EU research grant, and also includes facilities for managing submissions and reviews. That part has however been difficult to use and is no longer actively used. There have been discussions about going over to the use of OJS or some similar open source software, but so far this has not been done.

The first four years the journal was struggling to get submissions and only published 3-5 articles per year. It was saved by the suggestion of one of the editorial board members to start publishing special issues, which previously had been deemed out of the question since the aim was to publish papers as soon as they had gone through the review process. Since 2001 the journal has regularly published more than half of its articles in special issues. The experience is, that researchers are more keen to publish in special issues than to submit individual papers. Also it is usually easy to outsource the whole process to volunteers acting as guest editors for an issue.

Looking at the competition of 3-4 subscription journals with similar topics, ITcon would really have benefitted from inclusion in Web of Science and getting an impact factor. One attempt was made, in 2006, but unsuccessfully. Currently the journal is "struggling" with a yearly output of between 20 and 40 articles. What probably has saved the journal (which has no income but is fully based on volunteer work and the access to a free server) is the tiered managerial structure of up to ten co- and junior editors, which helps in spreading the workload of overseeing the review of submitted manuscripts. It can thus be characterized as a collective endeavor.

\section{Journal of Medical Education Online}

The idea of the Journal of Medical Education Online, abbreviated MEO, came from the founding editor's dissatisfaction around 1995 with how traditional academic publishers were ignoring the new opportunities offered by the Internet. After discussions with several colleagues, David Solomon originally envisaged MEO as a forum for knowledge exchange for both researchers and educators in the field, with a peer-reviewed journal as the centerpiece (Solomon, 2007). Over the years the additional features did not really catch on, but the peer-reviewed section has remained. After a few struggling years with below ten published articles per year the journal started to rapidly gain momentum reaching 100 yearly submissions in 2006 . 
399 Similar to many other journals with a heavy involvement of the editor-in-chief MEO has

400 changed publishing venue according to the editor's affiliation, depending on his employer

401 allowing a considerable input of work time. In the case of MEO the editor in addition to

402 overseeing the reviewing spent a lot of time on developing both the publishing and workflow

403 platform during the first ten years of the journals existence. In 2005 the rapidly grown

404 submission flow necessitated a restructuring of the editorial process so that a number of co-

405 editors helped share the burden. There were also plans to move the journal back to the original

406 university in Texas and for new people to take over the responsibility of the journal, but these

407 plans were partly upset by hurricane Katrina. Instead, one of the people, Ann Frye joined David

408 Solomon in co-editing the journal.

409

410 An important goal for the journal has all along been indexing in major indexes, including

411 Medline. A prerequisite for getting accepted in that index was the formatting of articles in XML

412 meeting the National Library of Medicine's (NLM) standards which requires a great deal of

413 expertise. The journal began charging an APC of 100 USD to cover the expense of using a

414 professional service to format articles and create an XML version meeting NLM standards. The

415 fee was raised to 200 USD a year later to cover professional copy-editing. Getting accepted in

416 Web of Science took an additional 3 years after the journal was accepted into Medline and

417 Scopus.

418

419

420

Around 2009 the two editors decided they wanted to use a professional publisher freeing them to

421 focus on the editorial tasks and providing professional level publishing services. Since an APC

422 of 200 USD had not reduced submissions they felt it was worth the risk of increasing the APC

423 considerably to have the journal professionally published. Discussions were started with a small OA publisher, Co-Action publishing. David Solomon knew and trusted the owners of the

424

425 company have worked with one of the principals of the company in forming OASPA. Initially,

426

427

428

429 the two editors retained $50 \%$ ownership with Co-Action receiving 50\% ownership for taking full financial responsibility for the journal. After two more years the original editors decided to step down as editors and gave full ownership to Co-Action and engaged new editors who receive a small fee for the work from the publisher. After an initial APC of 600 USD the APC has been increased in several increments to 1500 USD, while the number of publications per year has

430 steadily increased.

431

432

\section{Information Research}

433 The origins of IR were in a newsletter from the centre of user studies at the department of 434 information studies at the university of Sheffield, which from 1990 was transformed into 435 Information Research News, which published working papers in print (Wilson, 1998). From 436 April 1995 a parallel electronic version was published and in 1997 the print version was ended. 437 Initially the focus was on publishing un-refereed papers from the department, but gradually the 438 focus shifted to peer-reviewed papers with mainly outside authors. The university provided 
439 indirect support in the form of the web server and allowing staff the time to work with the 440 journal.

441

442 Later as the editor retired the journal has shifted locus. The journal home page currently says 443 about the journal: "It is privately published by Professor T.D. Wilson, Professor Emeritus of the 444 University of Sheffield, with in-kind support from Lund University Libraries, Lund, Sweden and 445 from the Swedish School of Library and Information Science". The home pages also contain a 446 plea for sponsorship either directly in money or in kind, as well as advertisements. In particular 447 the journal is seeking volunteers to help in copy-editing or formatting. In a recent web survey of 448 readers or authors (Wilson, 2012) the respondents were directly asked how likely they would be 449 to continue submitting articles to the journal if it had to start collecting APCs.

450

451 The journal has a stable output of four issues a year. The journal also contains book reviews, 452 conferences announcements etc. It is highly ranked in the rankings of information system 453 journals in many countries.

454

455

456

457

458

459

460

461

462

463

464

465

466

467

468

469

470

471

472

473

474

475

In contrast to many other 'indie' journals, Information Research has remained with html for the published papers, assuming readers would read directly from the screen. This format enables hyperlinking references in the text with the list of references.

The key to success for IR seems to have been in quite rapidly being able to publish a full journal with quarterly issues, at a time when major publishers were just starting to publish electronic versions of their paper journals. Probably early indexing in Web of Science, with a resulting impact factor, has also helped the success of the journal.

Despite having its origins in a print departmental newsletter, we feel that Information Research can be characterized as an 'indie' journal, especially after severing the ties with mother organization.

\section{Electronic Journal of Geotechnical Engineering}

This is an interesting case of an 'indie' journal turned predatory. Published by a now retired professor from an American university, the first issue in 1996 contained invited papers after which the journal was a typical struggling 'indie' journal with a slowly rising publication volume from 4 to 33 papers between 1997 and 2007. After that the volume has dramatically risen to 628 in 2014. Jeffrey Beall wrote a blog accusing the journal for having turned predatory in July 2015 (Beall, 2015). Currently the journal pages say "editorial fee is $\$ 500$ for the entire editorial and publishing work. Following the "supply and demand" rule of economics, this may be modified". 
476 The journal website still has an amateurish 1990's feel and look (authors are instructed that they

477

478

479

480

481

482

483

484

485

486

487

488

489

490

491

492

493

494

495

496

497

498

499

500

501

502

503

504

505

506

507

508

509

510

511

512

513

514

can also send the files on floppy disks!) and authors sign over the copyright to the journal.

\section{First Monday}

The first publisher of First Monday was curiously a Danish commercial publisher (Munksgaard) that was keen on experimenting with the new medium that the Internet offered. In 1999 the journal was bought by the editor Edward Valauskas, whose idea the journal had been from the start, with two colleagues (Pauli, 2011). Valauskas had all the time insisted that the journal be OA and that authors retain copyright, whereas Munksgaard had planned for the journal to evolve into a subscription journal after an initial open offering. Since then the journal has been hosted by the University of Illinois in Chicago and is currently using the OJS platform.

First Monday is published on the first Monday of each month, a reference back to the schedule of the first scholarly journal: Philosophical Transactions of the Royal Society. For a journal with no monetary budget it is quite amazing that it has published more than 1,500 articles, and despite the fact that the journal is not indexed in the Web of Science. One of the reasons for the popularity of the journal is that it is a multidisciplinary journal about the phenomenon Internet and that it has achieved a strong following in that niche area.

In 2011 the acceptance rate was as low as $15 \%$, which means that there is a lot of work behind each published article.

\section{Conclusions}

The 'indie' journals that comprise this study are children of their time, early pioneers in adopting a disruptive innovation for scholarship. With no or very little subscription income, and authorfees being an unestablished concept, the circumstances for running an independent journal was certainly a challenge in the 1990s and early 2000s. This study is limited to observing the sustainability trajectories of early 'indie' journals, the thousands of similar journals founded since then might have very different characteristics and warrant focus in future studies.

Nowadays the overall scene for launching OA journals looks very different than it did some 20 years ago. Currently there are a few specialized OA publishers and also the big established subscription publishers. The norm nowadays is also increasingly to collect APCs. Nevertheless early 'indie' journals have played an extremely important role in promoting OA, and some 'indie' journals have become important journals in their niche areas. Comparing the longitudinal publishing and citation metric trajectories of 'indie' journals to commercially-operated counterparts could also be a potential avenue for future studies to explore. 
515 The quantitative study shows that even successful 'indie' journals tend to be rather small, the 516 median being 18 articles per year. A fairly large share of articles is in the social sciences and 517 humanities. Areas such as mathematics and earth sciences have, however, grown in importance 518 over the years. Looking at the mortality rate of journals it is evident, that the years 6-9 are crucial. 519 The initial enthusiasm can sustain even a very low volume journal for a while, but after the 520 journal has to have a reasonably good inflow of manuscripts, both to be able to ensure the quality 521 of published articles as well as credible article numbers. We also already found that $8 \%$ of the 522 surviving 'indie' journals have started collecting APCs as a means to ensure enough revenue to 523 keep the journal running.

524

525 The cases studies demonstrate that remaining pioneer journals could consider exploring 526 alternative scenarios in order to ensure survival. Journals operating in the hard sciences may well 527 start charging APCs, given that mechanisms for funding these are evolving in many countries. 528 An important issue for all such journals lacking the backing of a professional publishing 529 organization, old or new, is to provide for a generation shift in the editor function.

530

\section{References}

532

533

534

535

536

537

538

539

540

541 Crawford, W. 2002. Free electronic refereed journals: getting past the arc of enthusiasm.

542 Learned Publishing 15(2):117-123. DOI: 10.1087/09531510252848881.

543

544 Edgar, B. D., \& Willinsky, J. 2010. A survey of scholarly journals using open journal system.

545

546

547

548

549

550

551

552

553

554

Beall, J. 2015. Beall's list: potential, possible, or probable predatory scholarly open-access pubilshers. Scholarly Open Access. Available at http://scholarlyoa.com/publishers/ (accessed 1 March 2016)

Björk, B-C., \& Turk, Z. 2006. The electronic journal of information technology in construction (ITcon): an open access journal using an un-paid, volunteer-based organization. Information Research 11(3):8.

Scholarly and Research Communication 1(2).

Gustafsson, T. 2002. Open access en empirisk undersökning om fritt tillgängliga journaler på Internet. Unpublished master's thesis, Swedish School of Economics and Business Administration.

Harter, S. P., \& Kim, H. J. 1997. ARCHIVE: Electronic journals and scholarly communication: a citation and reference study, Journal of Electronic Publishing 3(2). DOI:

http://dx.doi.org/10.3998/3336451.0003.212. 
555 Hedlund, T., Gustafson, T., \& Björk, B-C. 2004.The open access scientific journal: an empirical 556 study. Learned Publishing 17(3):199-209. DOI: 10.1087/095315104323159621.

557

558

559

560

561

562

563

564

565

566

567

568

569

570

571

572

573

574

575

576

577

578

579

580

581

582

583

584

585

586

587

588

589

590

591

592 Wilson, T. D. 2012. Report on a survey of readers of Information Research. Information

593 Research 17(4).

Hitchcock,S., Carr, L., \& Hall, W. 1996. A survey of STM online journals 1990-95: the calm before the storm. Available at http://journals.ecs.soton.ac.uk/survey/survey.html (accessed 1 March 2016)

Morris, S. 2005. The true costs of scholarly journal publishing. Learned Publishing 18(2): 115126. DOI: $10.1087 / 0953151053584975$.

Morrison, H. 2016. Small scholar-led scholarly journals: can they survive and thrive in an open access future? Learned Publishing 29(2): 83-88. DOI: 10.1002/leap.1015.

Odlyzko, A. 1997. The Economics of electronic journals. First Monday 2(8).

Pauli, M. 2011. First Monday - The first of its kind: a 15-year-old open access journal about the internet, catering to a diverse audience. Available at http://www.oastories.org/2011/09/denmarkus-journal-first-monday/ (accessed 1 March 2016)

PKP. 2016. OJS Usage - Public Knowledge Project. Available at https://pkp.sfu.ca/ojs/ojs-usage/ (Accessed 30 March 2016)

Redhead, C. 2015. Growth of OA-only journals using a CC-BY license. Available at http://oaspa.org/growth-of-oa-only-journals-using-a-cc-by-license/ (accessed 1 March 2016)

Shen, C., \& Björk, B-C. 2015. 'Predatory' open access: a longitudinal study of article volumes and market characteristics. BMC Medicine 13(230). DOI: 10.1186/s12916-015-0469-2.

Solomon, D.J. 2007. Medical Education Online: a case study of an open access journal in health professional education. Information Research 12(2).

Wells, A. 1999. Exploring the development of the independent, electronic, scholarly journal. Unpublished master's thesis, University of Sheffield.

Wilson, T. D. 1998. Information Research: a case study in the free electronic publication of research. VINE 28(2):10-16. DOI: http://dx.doi.org/10.1108/eb040681.

594

595 